\title{
70. Formation of Tibetan Plateau Considered from the Wandering of the Pole.
}

By Hantaro NAGAOKA and Toshiaki ShIRAI.

Institute of Physical and Chemical Research and Earthquake Research Institute, Tokyo.

(Comm. by H. NagaoKa, M.I.A., June 12, 1933.)

As stated in the previous communication, ${ }^{1)}$ there are two stationary points $O$ and $O^{\prime}$ on the equator, if the pole wanders in a meridian plane. The actual motion of the pole, deduced from the climate of the past times, is however complicated, so that the above approximation only applies to the displacement of the earth's axis from the beginning of the quarternary to the present time. If the meridians passing through the pole during its motion do not show great deviations, the points corresponding to $O$ and $O^{\prime}$ do not remain stationary, but trace out an equatorial curve, having the neighbourhood of its boundary elevated, compatible with the rotation of the earth at that geological period, if the motion of the pole be sufficiently slow to complete the plastic deformation. A good instance is afforded by Tibet during the mesozoic age.

Suess assumes the existence of a shallow sea named Tethys, which extended from Europe to Northern India in the late palaeozoic age, comprising a great part of Asia Minor, Persia, Turkestan, and N. China. During the mesozoic age, the normal through the earth's centre to the osculating plane of the curve traced by the wandering pole cut the surface near the southern border of Tethys in the vicinity of the Tibetan boundary, went further east, then making a round, turned westward and formed an incomplete loop through Tibet, passed over to Persia in the cretaceous; during the eocene it passed twice through the Caucasus describing nearly the same route, and went over to Europe during the tertiary age. The course thus taken by the quasi-stationary point is shown in Fig. 1: $T$ is the position in the middle of the triassic, $J$ in the jurassic, $C$ in the cretaceous, and $E$ in the eocene. The curve traced by the pole is similarly shown in Fig. 2.

Assuming the length of periods to be $70 \cdot 10^{6}$ for the triassic,

1) Nagaoka: Proc. 9 (1933), 239. 
Fig. 1 .

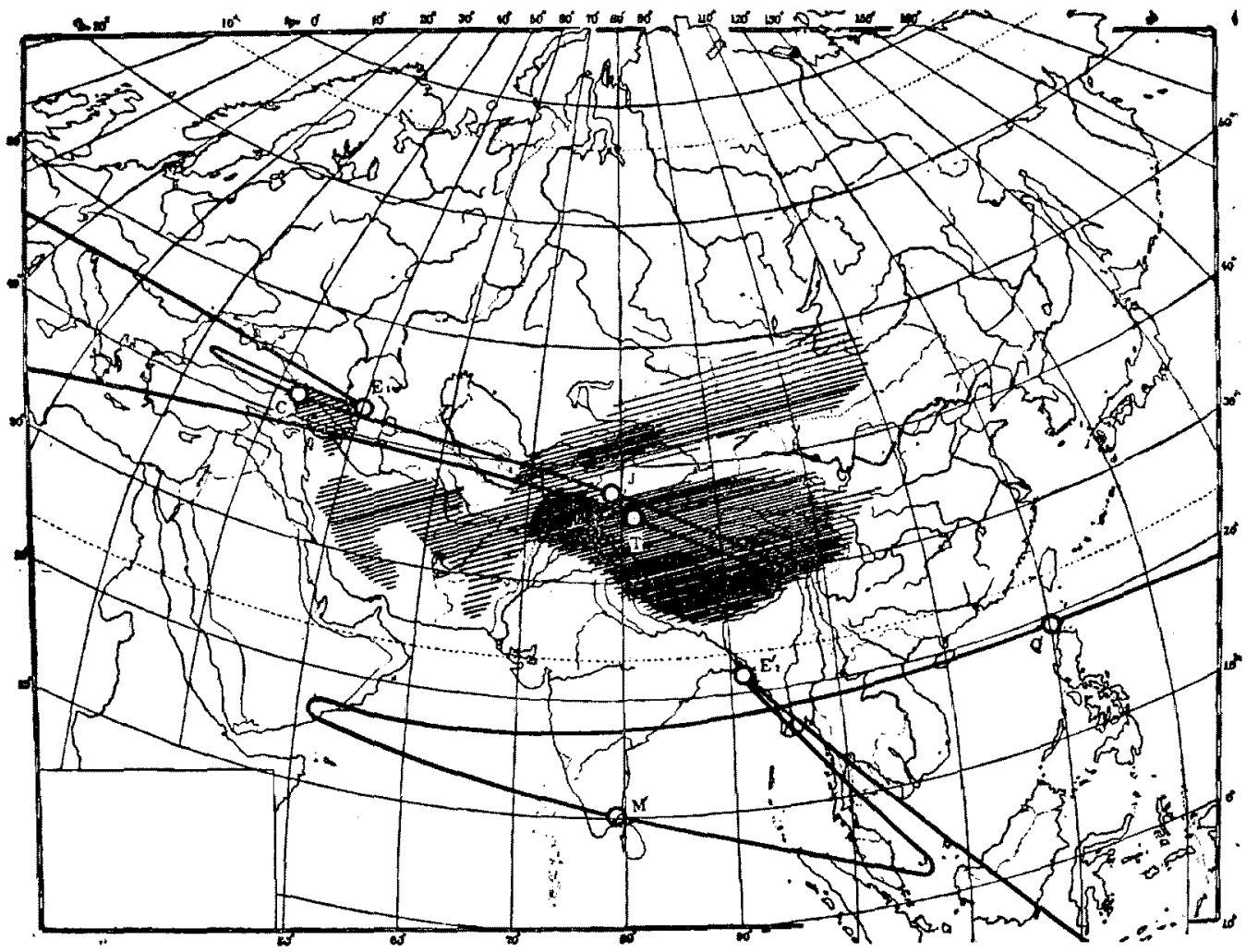

$T:$ triassic ; $J$ : jurassic; $C$ : cretaceous ; $E$ : eocene corresponding to $O$. $E_{2}^{\prime}$ : eocene corresponding to $O^{\prime} ; E_{1}$ belongs to first osculating plane at $E$ (Fig. 2), $E_{2}^{\prime}$ to the second; $M^{\prime}$ : miocene; $Q^{\prime}$ : quarternary.

Fig. 2.

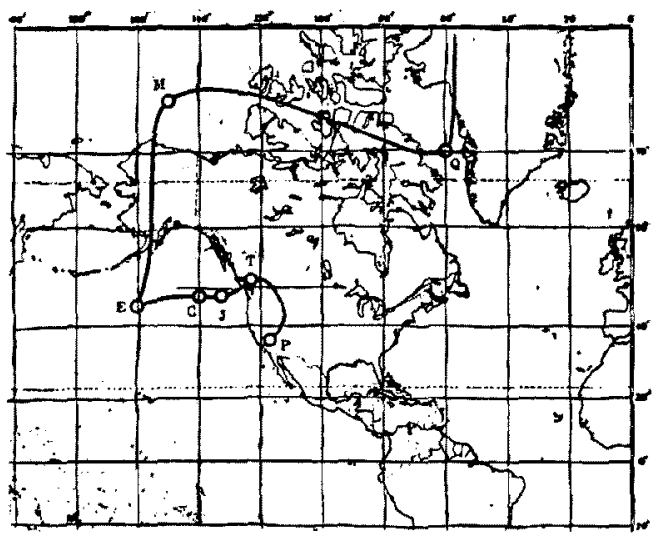

Position of N. Pole

for permian $(P)$, triassic $(T)$, jurassic $(J)$, cretaceous $(C)$, eocene $(E)$, miocene $(M)$, quarternary $(Q)$. 
No. 6.] Formation of Tibetan Plateau Considered from the Wandering of the Pole. 245

$50 \cdot 10^{6}$ for the jurassic, and $40 \cdot 10^{6}$ years for the cretaceous, the quasistationary point no doubt occupied more than a hundred million years to describe a Tibetan loop during the quiescent geological periods. This slow change at the equator is sufficient to make the plastic deformation reach its ultimate value.

During these periods, the difference of the equatorial axis from the polar was much greater than it is now; in other words, the elevation about the loop for a few degrees of the earth's arc was more conspicuous than during later ages. The vicinity of the loop, though at first placed in a shallow sea Tethys, gradually rose during the triassic and jurassic periods to the surface, as the action was steadfast and continued over 100 million years, constantly in the same sense of the upheaval. After the cretaceous, the motion of the pole became faster, and on entering the tertiary stage more rapid. Owing to the slow response of the crust to the state of hydrostatic equilibrium, the upheaval was most remarkable near the loop, and gradually decreased towards the west. Thus the high plateaus of Tibet and Hindukush appear to have been formed; though gradually decreasing in height by the shortening of the duration of the quasi-stationary action, the upheaval extended from Afghanistan and Persia to Asia Minor and Europe. The formation of the steppes seems to belong to the same period. The doubly crossed small area north of Asia Minor evidently coincides with Caucasus. Thus Tethys gradually disappeared, leaving some of its remnants.

During the formation of the Tibetan plateau, the condition of isostasy must have been nearly fulfilled, as it is necessary for equilibrium. Whether Tibet rose to the present height during the mesozoic is a question; we have further to consider the upheaval produced by the wandering of the quasi-stationary equatorial points during the eocene and the miocene, as shown in the diagram. The point at these times traversed India, and perhaps caused renewed upheaval. The uprise of the Himalayan range appears to have influenced the height of the plateau during the tertiary age. The persistent action of many million years during the mesozoic seems to have left permanent effect in preserving the stability of the plateau, which though somewhat eroded, still keep its ancient record of the plastic material rising several kilometres from the borders of Tethys.

Uhlig has given a chart of the world during jurassic period, in which Tibet was still under water. As the geology of Tibet is still in the dark, we cannot give much credit to a result of conjectural 
work. Tibet was probably quite high during the jurassic period according to the arguments here advanced.

The antipode to Tibet lies in the Pacific not far from South America. The elevation of the sea bed, which may be considered as arising from the same cause acting simultaneously with Tibet, is indicated in charts representing the depth of the Pacific Ocean, and is known as Easter Divide. The upheaval is not so great as for Tibet; it is partly accounted for by the greater solidity of ocean bed than the continental crust. Careful soundings will probably reveal how the sea bed was affected by the steady upheaving action during the mesozoic age. 